\title{
The Density of Gold-Silver-Copper Alloys and its Calculation from the Chemical Composition
}

\author{
J C Kraut and W B Stern \\ Geochernical Laboratory, Institute of Mineralogy and Petrography, \\ Bernoullistrasse 30, CH-4056 Basel, Switzenland
}

On the assumption that the contribution of a component metal to the density of an alloy is linearly related to the density and concentration of this metal in the alloy it is possible to calculate the values for the density of the system as a whole. Deviation from this behaviour occurs in the alloys formed by the metals of the copper group, and this is significant in the study of gold coins. Although the pure elements gold, silver and copper and their binary and ternary alloys crystallize mainly in the cubic face-centred form, the densities of these alloys do not display a linear correlation with the chemical composition (at\%). This is due mainly to the effects of ordering and disordering in the alloys as is described in this paper.

In order to calculate the density of gold-silver-copper alloys from chemical analysis, fitting curves are proposed for the binary and the ternary systems. The calculated densities correlate with experimental data from the literature, within an error range caused mainly by the uncertainty of the experimental density determined by means of Archimedes' principle.

\section{BINARY SYSTEMS}

When investigating gold coins it is of interest to prove whether the coins have been exposed to processes or conditions resulting in changes in their surface composition (eg blanching or depletion gilding). Eliminating less noble components from the surface gives an impression of higher gold content in the bulk of the coins. Using non-destructive methods, the densities of the coins determined experimentally may be compared with those calculated from the compositions obtained by surface analysis using X-ray fluorescence. Since there is not in any case a linear dependency of the densities of the pure metals gold, silver and copper and their binary and ternary alloys from composition, it is important to estimate the deviations from linearity due to the effects of ordering and disordering of the lattices.

The nearly identical radii of silver and gold (1.44 $\AA$, 1a) enable complete solid-solution, whereas the different atomic radii of silver and copper $(1.28 \AA, 1 \mathrm{a})$ induce a considerable miscibility gap $(2,3)^{1}$. Accordingly, $\mathrm{Cu}-\mathrm{Ag}$ alloys do not form an ordered phase at a molar composition of $1: 1$ in contrast to AuAg alloys which display an $\mathrm{AuAg}$ phase at temperatures below $800^{\circ} \mathrm{C}$ (4).

The binary system $\mathrm{Au}-\mathrm{Cu}$ displays three distinct phases, $\mathrm{AuCu}, \mathrm{Au}_{3} \mathrm{Cu}$ and $\mathrm{AuCu}_{3}$ existing at low temperatures $(5-9)$, and a superstructure of $\mathrm{Au}_{2} \mathrm{Cu}_{3}$ has been discribed $(10,11)$. In addition to the facecentred cubic lattice of the three binary systems, facecentred tetragonal and orthorhombic distorted phases also occur in gold-copper alloys $(5,12,13)$.

Above $410^{\circ} \mathrm{C}$ the Au-Cu phase displays an fcclattice with copper and gold atoms being statistically distributed. At temperatures less than $410^{\circ} \mathrm{C} \mathrm{AuCu}$ changes to an ordered orthorhombic, and below $385^{\circ} \mathrm{C}$ to a face centred tetragonal lattice $(8,9,13)$. When the molar ratio deviates slightly from $1: 1$, an orthorhombic distortion occurs, ie a reduced c- and an enlarged baxis. X-ray diffraction patterns reveal a superstructure having a ten times larger $b$-axis $(12,14)$.

The different modifications are the reason for the discrepancy between experimentally determined densities and those linearly calculated from chemical analysis. At a molar ratio of $1: 1$ the deviation may amount to $6 \%$-rel. in $\mathrm{Au}-\mathrm{Cu}$ alloys. $\mathrm{Cu}-\mathrm{Ag}$ alloys

1 Recently new values for the radii of $\mathrm{M}(\mathrm{I})$ species of gold, silver and copper have been suggested and calculated considering the effect of relativistic contraction (1b). 


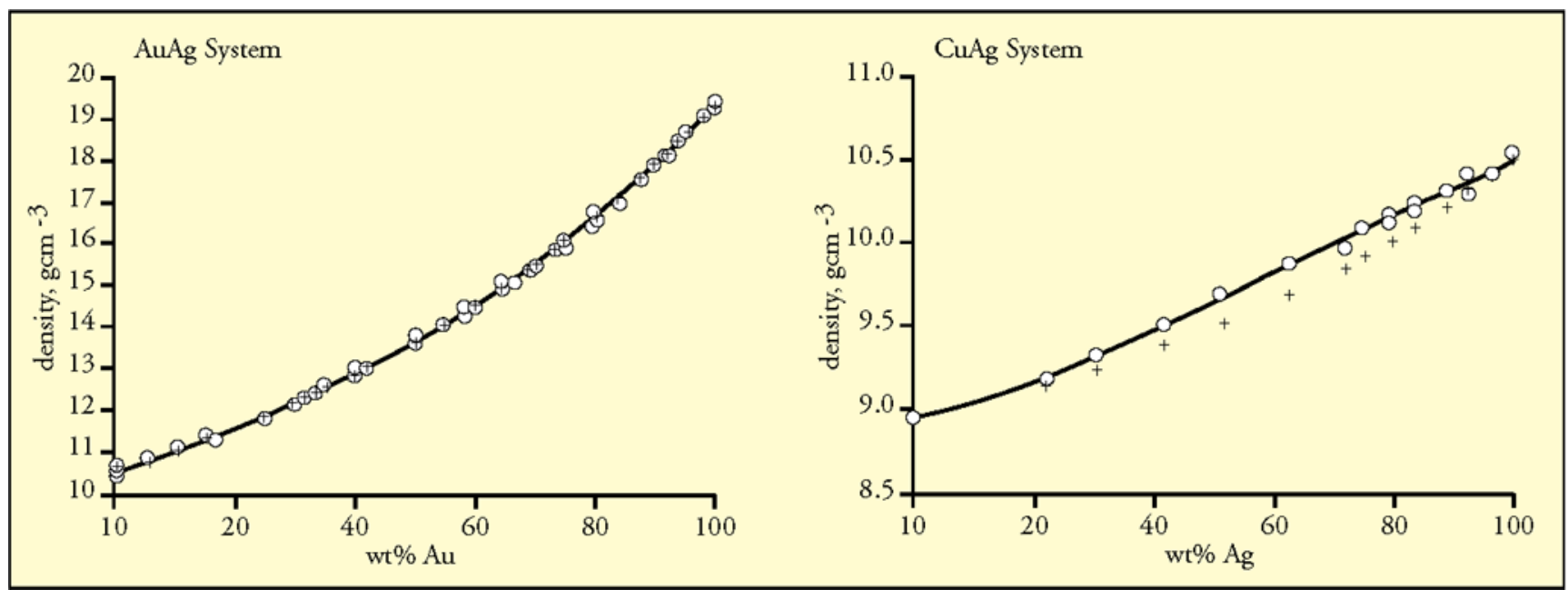

Figures 1 and $2 \mathrm{Ag}-\mathrm{Au}$ and $\mathrm{Cu}-\mathrm{Ag}$ Systems: Measured densities (o) of the cubic unordered phase vs composition (wto) of AgAuand CuAg-alloys and densities calculated by addition of the proportional amounts of the densities of the pure elements ( + ). The measured densities of the Ag-Au system show a linear dependency on the composition. The densities of the Ag-Cu system are, however, higher than expected for a linear dependency on the composition.

display maximum deviations of $1.5 \%$-rel. at $\mathrm{Cu}: \mathrm{Ag}=$ $1: 1(2,9)$. Figures 1 to 3 show the deviations between calculated $(t)$ and measured $(0)$ values.

Measured densities correlate with the state of ordering of the alloys, which is dependent on thermal treatment. In the unordered cubic state the lattice parameter is higher than is expected by linear correlation with composition. It is assumed that some of the smaller copper atoms are placed in between the regular lattice positions, and this leads to the expansion of the lattice (15). The deviation rises up to $0.0305 \mathrm{~A}$ $(0.8 \%$-rel.) in alloys containing 50 at $\%$ gold (16). By heating the samples the systems are able to change to a cubic ordered state of higher density in which only regular lattice positions are occupied. At a composition of $\mathrm{Cu}: \mathrm{Au}=1: 1$ the lattice planes alternate between those occupied by copper and those occupied by gold $(5,17)$. If the c-axis is shortened, the planes come closer to each other, leading to a larger overlap of the electron orbitals. This stabilizes the resulting tetragonal state. Bonding orbitals here seem to be orientated along the c-axis, while anti-bonding orbitals are orientated along the a-axes within the planes. Hence distances between similar atoms are enlarged and the cell volume increases. The density of the tetragonal state is therefore slightly lower than that of the ordered cubic state (Figure 3). At higher temperatures or compositions outside the range of $1: 1$ or $1: 3$, copper and gold are statistically distributed on the lattice positions. The cubic state is formed, in which no direction is favoured. Consequently the electrons are highly directionally degenerated. Hence the entropy of the electronic-gas is higher, and the free energy of the system (expressed by the equation $\delta \mathrm{F}_{\mathrm{e}}=\delta \mathrm{U} e-\mathrm{T}_{\mathrm{S}} \mathrm{S}_{\mathrm{e}}$ ) has a negative value (5). The cubic state therefore is formed spontaneously.

Even in 1930 the non-linearity between the lattice parameter of $\mathrm{Au}-\mathrm{Ag}$ alloys and the atomic ratio had been noticed, and a parabolic correlation curve was proposed by Sachs and Weerts (18) in order to determine the chemical composition from X-ray patterns.

Table 1 Equations for the Calculation of the Density of Binary Systems of Gold, Silver and Copper

$\begin{array}{lccc}\text { System } & \text { References } & \text { Equation } & \text { Figure } \\ \text { I } \mathrm{Ag}-\mathrm{Au} & \mathrm{II}, 18,19,20 & \mathrm{D}=0.193 \mathrm{a}+0.105 \mathrm{~b}-[4 * 10(-4) * \exp (0.005 \mathrm{a})] \mathrm{ab}(\mathrm{I}) & \mathrm{I} \\ 2 \mathrm{Cu}-\mathrm{Ag} & 4,19,20 & \mathrm{D}=0.0896 \mathrm{c}+0.105 \mathrm{~b}-[1.2 * 10(-5) * \exp (0.02 \mathrm{c})] \mathrm{cb}(2) & 2 \\ 3 \mathrm{Cu}-\mathrm{Au} & 11,17,21 & \mathrm{D}=0.193 \mathrm{a}+0.0896 \mathrm{c}-[5 * 10(-4) * \exp (0.01 \mathrm{a})] \mathrm{ac}(3) & 3\end{array}$




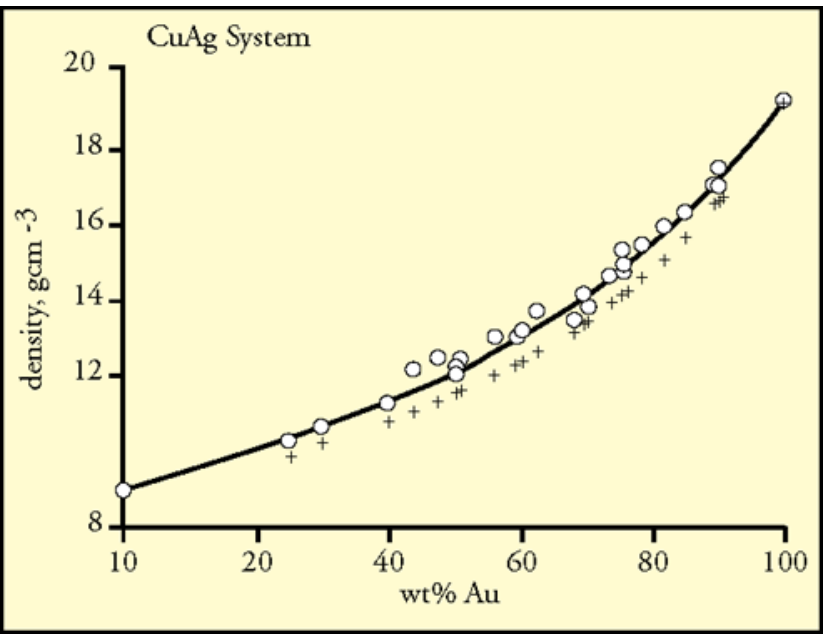

Figure 3: Au-Cu System: The experimentally determined values of the cubic unordered phase are distinctly higher than would be expected for a linear dependency on the composition. The densities of the ordered terngonal phase $\left(o^{5}\right)$, which is formed at

compositions between 70 and $80 \mathrm{wt} \%$ by beating up to $385^{\circ} \mathrm{C}$, are lower than that of the unordered state.

The solid lines show the densities calculated using Equations 1, 2, and 3 , and are dependent on the composition (in wt\%) for the cubic unordered phases of the systems.

Since the density of noble metals and their alloys can be determined accurately and relatively simply and non-destructively by Archimedes' principle, this method can be used to estimate the chemical composition. Hence, fitting curves were calculated for $\mathrm{Cu}-\mathrm{Ag}, \mathrm{Cu}-\mathrm{Au}$ and $\mathrm{Ag}-\mathrm{Au}$ alloys correlating weight percentages with data from literature $(11,17-20)$ using Equations 1 - 3 (Table 1).

Assuming an error of at least 0.5 to $1 \%$-rel. for the experimental density determination (slightly more than the symbol size of Figure 1 to 3 suggests) it follows that the calculated densities fit well within the error band of literature data.

\section{TERNARY SYSTEM}

The phases and lattice types present in binary alloys also exist in the ternary Au-Ag-Cu system. Small amounts of gold may be incorporated into the $\mathrm{Cu}-$ and Ag-rich phases which develop above silver concentrations of $15 \mathrm{at} \%$ in analogy with the miscibility gap of $\mathrm{Ag}-\mathrm{Cu}$ systems $(21,22)$. According to elemental ratios, $\mathrm{AuCu}$ and $\mathrm{AuCu}_{3}$ may be present along with silver-rich phases (23). $\mathrm{AuCu}$ and $\mathrm{AuCu}_{3}$ are stable at low temperatures only; and at higher temperatures the formation of distinct $\mathrm{AuCu}$ phases and of superstructures is suppressed when the silver content exceeds $5 \mathrm{at} \%$ (21). At a silver content of less than $5 \mathrm{at} \%$ and temperatures below $360^{\circ} \mathrm{C}$, the tetragonal phase of $\mathrm{AuCu}$ is the most stable. Between 360 and $385^{\circ} \mathrm{C}$ the orthorhombic structure occurs and above $385^{\circ} \mathrm{C}$ the cubic structure is formed (23).

The density of ternary alloys may be presented in a 3-dimensional plot, as shown in Figure 4. The density may be calculated using Equation 4:

$\mathrm{D}=1.004 \mathrm{a}^{\prime} \mathrm{D}_{\mathrm{Au}}+1.03 \mathrm{~b}^{\prime} \mathrm{D}_{\mathrm{Ag}}+0.096 \mathrm{c}^{\prime} \mathrm{D}_{\mathrm{Cu}}+\mathrm{x}-\mathrm{y}(4)$

$x=0.35\left[\cos \left(45+0.45 a^{\prime}\right)+\cos \left(45+0.45 b^{\prime}\right)+\sin \left(a^{\prime}\right)\right]$ $y=0.005^{*}\left(a^{\prime}+b^{\prime}\right) * \cos \left(0.9 c^{\prime}\right)+0.2^{*} \cos \left(3.2 c^{\prime}\right)$

with $a^{\prime}=$ at $\% \mathrm{Au} ; b^{\prime}=a t \% \mathrm{Ag} ; c^{\prime}=$ at $\% \mathrm{Cu}$

$\mathrm{D}_{\mathrm{Au}}=$ density of gold, in $\mathrm{g} \mathrm{cm}^{-3}$

$\mathrm{D}_{\mathrm{Ag}}=$ density of silver, in $\mathrm{g} \mathrm{cm}^{-3}$

$\mathrm{D}_{\mathrm{Cu}}=$ density of copper, in $\mathrm{g} \mathrm{cm}^{-3}$

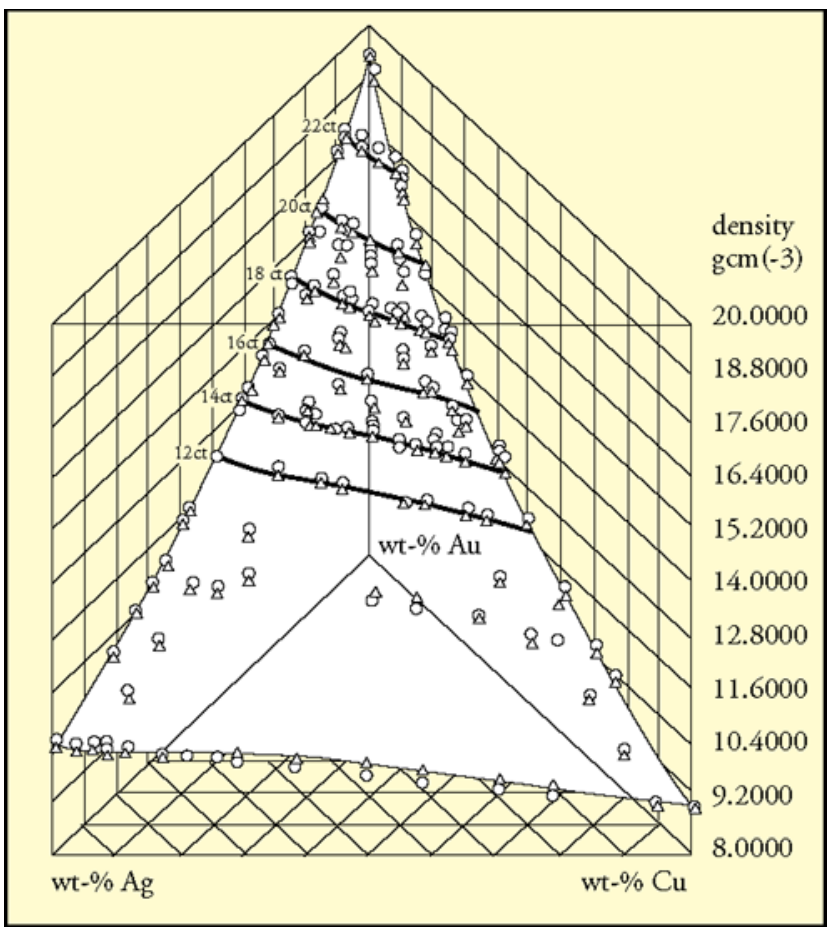

Figure 4: Measured and Calculated Densities for the Ternary System Au-Ag-Cu Deviation between measured densities ( 0 ) and those calculated for a linear dependency on density $(\Delta)$ derived from chemical composition for the ternary system. The prism is formed by the axes expressing the weightpercentages of the elements as the base and the horizonial axis expressing the density. The calculated values are mostly lower than those obtained by other authors. The lines within the triangle represent the systems containing $50,58.5,66.6,75,83.3$, and $91.7 w \%$ gold. 
This calculation, with its error of up $3.1 \%$-rel., is reliable and comparable with that for binary systems. The equation represents the density, assuming cubic phases, but does not account for the possible presence of porosity (24).

Equation 4 may be of importance in numismatic studies when the experimental bulk density is compared with the calculated density obtained from surface analysis (eg by X-ray fluorescence analysis, $\mathrm{XRF}$ ). Hence, surface treatments (depletion processes like blanching and plating) may be detected easily by entirely non-destructive methods.

\section{ACKNOWLEDGEMENTS}

This work is part of a $\mathrm{PhD}$ project at the University of Basle, the objective of which is the analysis of Roman gold coins using appropriate methods.

The authors would like to thank M. Kirschen for making available the drawing program for Figures 4 and 5 , and $\mathrm{C}$. Hetherington for corrections.

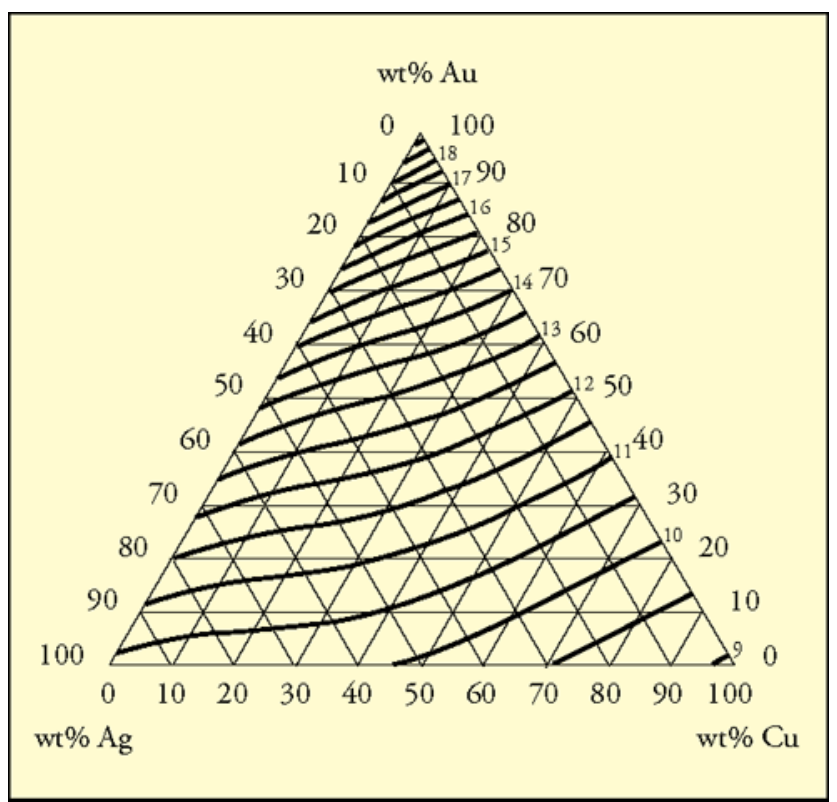

Figure 5: Chemical Composition (wt \%) and Archimedes Densities for the Ternary System Au-Ag-Cu The solid lines represent the values of equal density, the values themselves are given by the small ciphers along the axis of the gold-copper-system. In the case of bigher contents of gold the lines are nearly parallel. Whereas the curves are shifeed towards higher values in the case of high contents of silver when the content of gold or copper decreases, as is seen for the values of 10 to $12.5 \mathrm{~g} \mathrm{~cm}^{-3}$. High contents of siluer lead to a decomposition of the alloy, due to the miscibility gap of copper and silver (21).

\section{ABOUT THE AUTHORS}

Prof Dr W B Stern is head of the Geochemical Laboratory at the Institute of Mineralogy and Petrology, Basel. He has worked on several projects in the field of archacometry, mostly using non-destructive X-ray analytical methods. J Kraut is working at the Geochemical Laboratory investigating gold coins of the Roman and Byzantine Empire.

\section{REFERENCES}

a) A.F Wells, 'Structural Inorganic Chemistry' Clarendon Press, Oxford 4th ed., 1975; b) W.S. Rapson, Gold Bull, 1996, 29, 143

2 M. LeBlanc and W. Erler, Amm. Phys, 1933, [5] 408, 321

3 E Raub, 'Die Edelmetalle und ihre Legierungen' Springer-Verlag, Berlin, 1940

4 J. Wolters, 'Der Gold-und Silberschmied', Rühle-Diebener-Verlag, Stuttgart, 1991

5 U. Dehlinger and L. Graf, Zt. Phys., 1930, 64, 359

6 G. Grube, G. Schönmann, F. Vuupel and W. Weber, Z Aporg. Allg. Chem, 1931, 201, 41

7 M. Leblanc, K. Richter and E. Schiebold, Ampa. Phys, 1928, [4] 86, 929

8 B. Predel, 'Heterogene Gleichgewichte', Steinkopf-Verlag, Darmstadt, 1982

9 H. Okamoto and T.B. Massalski, 'Phase Diagrams of Binary Gold Alloys', ASM International, 1987, 76

10 E Gebhardt, Allg. Metallk.', od. M. Hansen, 1939-46, 31, 68

11 M. Bergman, L. Holmlund and N. Ingri, Acta Chem Scarn, 1972, 26, 2817

$12 \mathrm{CH}$. Johansson and J.O. Linde, Amm. Phys, 1936, [5] 25, 1

13 E. Vogt, Amm. Phys, 1932, [5] 14, 1

14 T. Uzuka, Y. Kanzawa and K. Yasuda, J. Dent. Res, 1981, 60 (5), 883

15 E. Zintl and S. Neumayer, Z. Elektrochem, 1933,39,86

16 L. Vegard and A. Kloster, Z. Krist., $1934,89,560$

17 N.W. Ageew and D.N. Skoyket, Aman. Phys, 1935, [5] 23, 90

18 G. Sachs and J. Weerts, Z. Phys, 1930, 60, 481

19 Gmelin's Handbuch der anorganischen Chemie', 'Silber' part $\mathrm{C}$ and 'Gold' systemnumber $62,8^{\text {th }}$ ed., Verlag Chemie, Weinheim, 1972

20 Landoldt-Börnstein, 'Eigenschaften der Materie in ihren Aggregatzuständen' Part 1, Springer-Verlag, Berlin 1971, p. 764

21 H. Bumm, Z. Metallk, 1939, 31, 318

22 M. Kogachi and K Nakahigashi, Jap. J. Appl Phys,1980, 19, 1443

23 E Raub, Z. Metalk, 1949, 40, 46

24 D. Ott, Gold Bull, 1997, 30, 13 